\title{
Review of recombinant human deoxyribonuclease (rhDNase) in the management of patients with cystic fibrosis
}

\author{
Tacjana Pressler \\ CF Centre, Dept. of Pediatrics, \\ Rigshospitalet, University \\ of Copenhagen Denmark
}

Correspondence:Tacjana Pressler Pediatric Department, Rigshospitalet Blegdamsvej 92100 Copenhagen $\varnothing$ Denmark

Email pressler@mail.dk

\begin{abstract}
The most important problem in cystic fibrosis (CF) lung disease is chronic airway inflammation and infection, which starts early in life. To prevent severe lung damage, it is important to mobilize as much sputum as possible from the lung on a daily basis. RhDNase is an enzyme that breaks down DNA strands in airway secretions, hydrolyzes the DNA present in sputum/mucus of CF patients, reducing viscosity in the lungs and promoting secretion clearance. Several well performed trials have proven its efficacy in young CF patients with mild disease as well as in older patients with more advanced lung disease. Daily inhalation of this agent slows down lung function decline and decreases the frequency of respiratory exacerbations. The drug is well tolerated by most patients independent of the severity of lung disease.
\end{abstract}

Keywords: cystic fibrosis, lung disease, recombinant human deoxyribonuclease

\section{Introduction}

Cystic fibrosis (CF) is a hereditary disease caused by mutations in the gene coding for the CF transmembrane conductance regulator protein (CFTR) which is involved in transmembrane ion conductance (Riordan et al 1989; Rommens et al 1989). The primary defect involves ion imbalance resulting in inspissated exocrine secretions, particularly in the pancreas, lung, liver and gastrointestinal tract. At birth, the primary manifestation is failure to thrive and/or meconium ileus due to gastrointestinal involvement including, in most cases, pancreatic insufficiency (Collins 1992; Riordan 2008). Once the disease is diagnosed and pancreatic enzyme supplementation combined with a high-fat diet begun, malnutrition can usually be avoided and the most troublesome symptoms are due to progressive pulmonary infection and inflammation, which are promoted by typically viscous CF mucus in the lung. While the lungs of CF patients appear normal at birth, postmortem studies of lungs from infants who died of meconium ileus identified mucus plugging in terminal bronchioles with emphysema secondary to obstruction of mucus filled bronchioles (Zuelzer et al 1949). A vicious circle ensues shortly after birth, characterized by thick mucus obstructing small airways and thus providing a niche for bacterial growth, infiltration of lung tissue by neutrophils as a component of the inflammatory response, discharge of neutrophil contents including the viscous polyanion DNA, and increasingly viscous mucus. The abnormal mucus leads to chronic lower airway infection and inflammation that starts mostly in infancy (Konstan et al 1994; Armstrong et al 1997; Rosenfeld et al 2001; Sagel et al 2001).

Extracellular DNA released by disintegrating inflammatory cells, is present in high concentrations in CF sputum (Chernick 1959; Smith et al 1988). This free DNA contributes to the abnormally high viscosity of CF sputum. It therefore forms an important target in the treatment of CF lung disease. Chronic infection and inflammation 
gradually reduce pulmonary function and induce irreversible lung damage. Double lung transplant is the only effective treatment in the terminal stages of CF lung disease. In 2006 in US, the median predicted survival age was 36.9 years (Cystic Fibrosis Foundation 2006). Death is usually due to irreversible lung damage and cardiopulmonary failure.

Treatment of CF lung disease is still symptomatic and focused on antibiotic treatment of lung infections, and facilitating removal of abnormal pulmonary secretions (Döring et al 2004).

According to current understanding of the pathogenesis of CF pulmonary disease, airway damage is result of a vicious cycle of inflammatory responses involving recruitment of large numbers of leukocytes, primarily neutrophils (Koch et al 1993). When neutrophils disintegrate, they release high concentrations of extracellular DNA. Polymerized DNA contributes to the increased viscosity of airways secretions. This free DNA contributes to the abnormally high viscosity of CF sputum. It therefore forms an important target in the treatment of CF lung disease. Impaired mucociliary clearance is an important problem in most patients with CF. Consequently, a major goal in the treatment of CF is to mobilize as much sputum as possible from the lung on a daily basis.

Until now, two drugs are established with a positive effect on mucociliary clearance in patients with CF: recombinant human DNase (rhDNase) and hypertonic saline (Robinson et al 1997; Houtmeyers et al 1999; Ratjen et al 2005).

\section{Biological rationale for rhDNAse therapy}

The biological rationale for rhDNAse therapy relates to the observation that purulent pulmonary secretions contain high concentrations of extracellular DNA released by disintegrating neutrophils.

Experiments in the 1950s and 1960s revealed that DNA is present in very large amounts $(3-14 \mathrm{mg} / \mathrm{mL})$ in purulent, but not in uninfected, lung secretions (Chernick et al 1961; Potter et al 1969). DNA, an extremely viscous polyanion, may contribute to the increased viscosity of lung secretions. In fact, lung secretions incubated in vitro with partially purified bovine pancreatic DNase show a large reduction in viscosity (Chernick et al 1961). Based on these observations, bovine pancreatic DNase I (dornavac or dornase) was approved in the US for human use in 1958. Numerous uncontrolled clinical studies in patients with pneumonia and one study in CF suggested that bovine pancreatic DNase I was reasonably safe and effective in reducing the viscosity of lung secretions (Lieberman 1968). However severe adverse respiratory reactions did occasionally occur, perhaps as a consequence of allergic reactions to a foreign protein.

The gene for human DNase was cloned from a pancreatic cDNA library in 1988 (Shak et al 1990) and the recombinant human DNase (rhDNase) has been synthesized. Because rhDNase is identical to human DNase, it can be used safely without risking the hazards associated with the use of animal proteins. Catalytic amounts of rhDNase greatly reduce the viscosity of purulent $\mathrm{CF}$ sputum, transforming it within minutes from a nonflowing viscous gel to a flowing liquid (Shak et al 1990).

In a multicenter open study the evolution of inflammation in CF patients with early lung disease and its modulation by rhDNase treatment, were studied (Ratjen et al 2005). Treatment with rhDNase over 18 months reduces DNA load in BAL fluid, which may have a positive effect on the clearance of lower airway secretions (Ratjen et al 2005).

\section{Safety of rhDNase treatment}

The safety of rhDNase has been assessed with respect to clinical adverse events and laboratory parameters (Aitken et al 1992; Ramsey et al 1993; Eisenberg et al 1997). In phase I studies, serum rhDNase concentration was measured at several time points following single and multiple inhalation of escalating doses of rhDNase in healthy subjects and in patients with CF. Only very low serum concentrations of DNase were observed. No anti-rhDNase antibodies were detected in each of the studies (Aitken et al 1992; Hubbard et al 1992). Therefore, it is concluded that systemic exposure to inhaled rhDNase was negligible. Since rhDNase was marketed, multiple studies have been performed on this drug (Jones et al 2003). RhDNase is now widely used for treatment of CF lung disease. This gave the opportunity to use long-term clinical data from patient registries for postmarketing surveillance. Hodson et al reported on rhDNase using the Epidemiologic Registry of Cystic Fibrosis (ERCF) (Hodson et al 2003; McKenzie et al 2007). At that time, the ERCF contained data on 13,684 CF patients. In general, detailed safety assessments of rhDNase indicated that this drug is well tolerated. Although development of adverse events was the most common reason for withdrawal from the studies, the incidence and nature of these events were similar in the groups of patients receiving rhDnase and those receiving placebo. Only alteration in voice (hoarseness), pharyngitis and laryngitis, was associated with 
administration of rhDNase (Aitken et al 1992; Ramsey et al 1993; Ranasinha et al 1993; Fuchs et al 1994; Eisenberg et al 1997).

\section{Clinical efficacy assed as improvement in pulmonary function and reduction in respiratory exacerbations}

Clinical trials of rhDNase were conducted to test the hypothesis that increased concentrations of polymerized DNA in purulent sputum contributes to the acute and chronic complications of $\mathrm{CF}$ and that administration of this agent would ameliorate such complications. The efficacy of aerosolized rhDNase in patients with CF has been investigated in a number of well designed dose-ranging and placebo-controlled studies in patients with mild to moderate lung disease. Mild to moderate lung disease was defined as a forced vital capacity (FVC) $\geq 40 \%$ of the predicted value.

The Phase II, dose-ranging studies of rhDNase was conducted (Ranasinha et al 1993; Ramsey et al 1993). Clinical stable adults and children with CF were eligible for enrollment in these placebo-controlled, double-blind trials. The duration of treatment in both studies was 10 days. Improvement in forced expiratory volume in 1 second $\left(\mathrm{FEV}_{1}\right)$ was evident within 3 days of initiating treatment. Ramsey et al (1993) found that a 10-day administration of once daily $0.6 \mathrm{mg}, 2.5 \mathrm{mg}$, or $10.0 \mathrm{mg}$ rhNase significantly improved $\mathrm{FEV}_{1}$ by $10 \%$ to $15 \%$ compared with placebo. In a second study, conducted by Ranasinha et al (1993), a 10-day administration of twice daily $2.5 \mathrm{mg}$ rhDNase improved $\mathrm{FEV}_{1}$ by $13.5 \%$ compared with placebo.

The first phase III study with rhDNase was a 24-week, multicenter, randomized, double-blind, placebo-controlled trial with a parallel-group design and open-label extension of 24 weeks (Fuchs et al 1994). In addition to lung function the study assessed the effect of rhDNase on the number of respiratory tract exacerbations and evaluated the effects of rhDNase on quality-of-life measures. Patients were recruited from 51 institutions and were eligible if they were 5 years of age or older, and had a FVC greater than $40 \%$ of the predicted value. The administration of rhDNase for 24 weeks to patients with CF resulted in a modest reduction in the risk of exacerbations of respiratory symptoms requiring parenteral antibiotics and a slight improvement in lung function. The administration of rhDNase also lessened dyspnea, increased the perception of general well-being, and decreased the severity of CF-related symptoms. All patients who completed the phase III double-blind study were eligible to participate in a 24-week open-label extension of the trial. The positive effects of rhDNase therapy were maintained throughout the extension. There is no clear consensus on the level of improvement in pulmonary function tests as significant clinical response in CF. The mean improvement in $\mathrm{FEV}_{1}$ of $5.8 \%$ observed with long term administration of rhDNase were associated with significant improvements in symptoms due to CF airways disease (dyspnea, cough, congestion) and more important, with a decline in the incidence of pulmonary exacerbations.

In a similar study the use of rhDNase in a 96-week randomized, double blind, placebo-controlled multicenter trial involving 574 children with CF and with well preserved lung function were reported (Quan et al 2001). In this 2-year study, young patients with $\mathrm{CF}$ and early lung disease receiving rhDNase had improvements in lung function and reduction in the risk of exacerbation of respiratory symptoms requiring intravenous antibiotics when compared with patients in a placebo group. Lung function in the rhDNase group was maintained at or above baseline values for 2 years (Quan et al 2001). Despite the milder lung disease in patients in this study, the $34 \%$ reduction in risk of exacerbation for the rhDNase group is similar to the reduction in risk of exacerbation seen in the previous 6-month study of patients with FVC $>40 \%$ predicted (Fuchs et al 1994). Because exacerbation appears to be a major risk factor for decline in lung function, decreasing the number of exacerbations would slow the decline in lung function (Konstan et al 2007).

A 12-week study examining the effect of inhaled rhDNase in a group of $320 \mathrm{CF}$ patients with advanced lung disease $\left(\mathrm{FEV}_{1}<40 \%\right.$ predicted) showed that patients receiving rhDNase had a statistically greater improvement in $\mathrm{FEV}_{1}$ than placebo group (McCoy et al 1996). The frequency of pulmonary exacerbations requiring parenteral antibiotics was not significantly reduced in the rhDNase-treated patients compared with placebo recipients. Although a trend toward reduction in overall hospitalization was observed in the rhDNase group, no significant difference was seen. This study demonstrates that rhDNase is not only effective but also safe in CF patients with advanced lung disease (McCoy et al 1996).

To evaluate the long term influence of rhDNase on disease progression, Shah et al (2001) conducted a case-controlled study with rhDNase over a period of 4 years. A cohort of patients with CF who have been treated with rhDNase were matched with a control group of patients with CF who had not received treatment with rhDNase. The patients were matched by pulmonary function, age, and then sex. 
There were significantly more infective exacerbations per patient year in the control group in comparison to the rhDNase group over the 4-year treatment period. Antibiotic requirements (days of intravenous antibiotic use per patient year) were also significant greater in the control group compared with the rhDNase group. This case-controlled study failed to show a statistically significant difference in the rate of decline in $\mathrm{FEV}_{1}$ between patients treated with rhDNase and untreated patients over the study period. However, there was a trend to suggest that longer-term treatment with rhDNase reduces the rate of decline in $\mathrm{FEV}_{1}$.

Most studies lack even basic microbiological data, but a large proportion of exacerbations in pulmonary disease in patients with CF are caused by Staphylococcus aureus and Pseudomonas aeruginosa (Petersen et al 1981). In a 12-month study an effect of rhDNase on the load of microbial pathogens in the lower respiratory tract was investigated (Frederiksen et al 2006). Overall, the number of positive cultures was significantly higher in the untreated group compared with the treated group. The most striking difference was found for $S$. aureus, with a 12 -month prevalence of $30 \%$ in the untreated group compared with $16 \%$ in the treated group $(\mathrm{p}<0.05)$. The lower infection rate may be associated with less respiratory exacerbations and less inflammation. In a longer perspective, DNase treatment will probably help in preventing the gradual tissue damage and irreversible loss of lung function, which is the consequence of sustained presence of pathogens in the lower respiratory tract.

In a post-marketing surveillance Hodson et al (2003) reported the results of treatment with rhDNase by comparing untreated patients (no rhDNase) with treated patients. Effects on $\mathrm{FEV}_{1}$ and on number of exacerbations per year were studied. In total, 2023 patients were eligible for analysis of $\mathrm{FEV}_{1}$ and 4299 patients were eligible for analysis of exacerbations. Overall, untreated patients experienced a decrease in mean $\mathrm{FEV}_{1} \%$ predicted of -1.1 over 1 year and -2.3 over 2 years. Patients treated with rhDNase had FEV higher than baseline after 1 year $(+2.5 \%$ predicted $)$ and were stable over the period of 2 years $(+0.3 \%$ predicted $)$. Compared with untreated patients, treated patients had a significant reduction in exacerbation frequency of -0.25 . This is equivalent to a reduction of 25 exacerbations per 100 treated patients per year. Younger patients gained most from treatment. This result is consistent with the general concept that early treatment of $\mathrm{CF}$, before chronic inflammation has led to irreversible lung damage, may be more effective in the long term (Armstrong et al 1995, 2005; Khan et al 1995).

\section{Inflammation}

Studies using spontaneously expectorated sputum have raised concerns that rhDNase may increase airway inflammation by releasing proinflammatory cytokines such as IL- 8 that are bound to DNA in airway secretions (Shah et al 1996; Perks et al 2000). The subsequent study was unable to demonstrate a promoting effect of rhDNase on IL-8 concentrations (Suri et al 2002). Currently, no data are available on the long-term effect of rhDNase on lower airway inflammation in CF. Given the positive effects on both airway clearance and frequency of pulmonary exacerbations, rhDNase could also exhibit an anti-inflammatory effect in CF airways. Paul et al (2004) studied lower airway inflammation over a 3-year period using bronchoalveolar lavage (BAL) in a cohort of patients with CF having mild lung disease. A total of 105 patients with $\mathrm{CF}$ (over 5 years of age) having normal lung function were randomized to receive $\mathrm{rhDNase}(2.5 \mathrm{mg}$ /day) or no rhDNase. Patients with a normal percentage of neutrophils in BAL fluid at baseline were not randomized and served as the control group. The percentage of neutrophils in the pooled BAL sample was similar in both randomized groups at baseline. A significant increase in neutrophils was observed over the 3 -year study period in both untreated patients and control subjects, whereas neutrophils remained unchanged in patients treated with rhDNase. Elastase activities and interleukin-8 concentrations also increased in untreated patients and remained stable in patients on rhDNase. It seems that an increase in neutrophilic airway inflammation found in $\mathrm{CF}$ is positively influenced by rhDNase treatment (Paul et al 2004). These data support earlier findings that rhDNase has a beneficial effect on metalloproteases in BAL fluid (Ratjen et al 2002) and would favor an early use of this drug in patients with CF having mild lung disease and support the evidence provided by the rhDNase early intervention trial study that demonstrated a positive effect of rhDNase on both lung function and pulmonary exacerbations in patients with CF having mild disease (Quan et al 2001).

\section{rhDNase treatment in young children with CF}

Studies have shown that rhDNase improves lung function and decreases exacerbation rate, and in 1993 rhDNase was approved for the management of CF patients with a FVC of greater than $40 \%$ of predicted in the US, Europe, and Australia.

In Europe, rhDNase is approved only for CF patients aged 5 years and older, since registration studies were 
only performed in this age category. In the US, rhDNase is approved for all ages. Surprisingly, no registration studies have been performed in children below the age of 6 to support this registration. Clearly, such studies are difficult to perform. However, these studies are urgently needed to establish safety and efficacy especially in infants' approval for Europe and Australia.

CF lung disease begins early in life (Balough et al 1995; Khan et al 1995; Kirchner et al 1996; Armstrong et al 2005) leading to suggestions that therapy directed at reducing or avoiding the development of airway obstruction should be started in infants and young children. Elevated DNA concentrations have been found in BAL fluid from infants with $\mathrm{CF}$ (Kirchner et al 1996; Ratjen et al 2005), suggesting a role for early treatment with rhDNase. Wagener et al (1998) showed that aerosolized rhDNase can be delivered to and are present in comparable amounts in the lower airways of younger and older children. Exposure to rhDNase appears to be safe over 2 weeks in infants and young children with CF.

The Epidemiologic Registry of Cystic Fibrosis (ERCF) was an observational study sponsored by Hoffmann-La Roche Ltd that operated in 9 European countries (Austria, Belgium, Denmark, France, Germany, Ireland, The Netherlands, Sweden, and the UK) between 1994 and 2000. After closure of the Epidemiologic Registry of Cystic Fibrosis (ERCF), a comprehensive safety analysis of rhDNase was performed. A planned subanalysis focused on children under 5 years old. During 655 patient-years of follow up in 328 ever-treated patients under 5 years old, serious adverse events (mostly pulmonary exacerbations of $\mathrm{CF}$ ) were slightly less frequent during treatment confirming the safety of rhDNase in CF patients of all ages. Children under 5 years old tolerate rhDNase at least as well as older patients (McKenzie et al 2007).

To assess the feasibility of measuring short-term effects of inhaled rhDNase on lung function, pulse oximetry, and symptom scores in infants and toddlers with stable CF the pilot study were performed (Berge et al 2003). Nine CF patients (0.7-1.9 years) were treated with nebulized rhDNase during 2 weeks. DNase treatment was well tolerated and lung function tests (measured with plethysmography and tidal rapid thoraco-abdominal compression technique) showed significant increased airway patency after treatment with rhDNase, but not after $\mathrm{NaCl} 0.9 \%$. This pilot study indicates that objective assessment of the effects of rhDNase is feasible in infants with CF who have little or no respiratory symptoms (ten Berge et al 2003). Nasr et al (2001) evaluated the ability of high-resolution computerized tomography (HRCT) of the chest to determine efficacy of inhaled recombinant rhDNase in $\mathrm{CF}$ patients younger than 5 years of age. A randomized, double-blind, placebo-controlled pilot study of 12 patients with CF younger than 5 years of age was conducted. The mean changes of HRCT scores between the rhDNase and placebo groups were found to be significant. There was improvement in the parents' assessments of patient well-being, with improvement in physical activity, decreased cough, sleep quality, and appetite in those subjects receiving rhDNase. The benefit of rhDNase treatment in young CF patients with well preserved lung function were confirmed by Quan et al (2001) in a multicenter, placebo-controlled, 96-week study.

\section{Controversies in rhDNase use}

Although clinical trials have shown that rhDNase significantly improves lung function in patients with $\mathrm{CF}$, it does not mean that all patients benefit from this treatment (Fuchs et al 1994; Shah et al 1995; Harms et al 1998). Different studies have shown a wide variation in the clinical response to rhDNase (Davies et al 1997; Bollert et al 1999; Cobos et al 2000). Numerous studies have been performed to elucidate the reason for the failure of rhDNase in certain CF patients and to evaluate strategies to overcome this (Chen et al 1999; Sanders et al 2006). Different treatments regimes, according optimal timing of rhDNase treatment in relation to physiotherapy, have been studied (van der Giessen et al 2007; Wilson et al 2007). Studies to compare different nebulizers have been conducted (Fiel et al 1995; Shah et al 1997).

It is a general principle that a registered nebulized drug like rhDNase should be aerosolized using only a nebulizer system that is considered appropriate by regulatory agencies and the responsible pharmaceutical company (Boe et al 2001).

Alternate-day dosing has been suggested (Suri et al 2002). The authors concluded that rhDnase could be given on alternate days as a similar improvement in $\mathrm{FEV}_{1}$ was shown compared with daily rhDNase administration. This study was conducted over relatively short period (12 weeks) and outcomes such as the number of respiratory exacerbations, weight gain, and quality of life may need a longer study to be able to show the differences.

\section{Conclusion}

The most important problem in CF lung disease is chronic airway inflammation and infection, that starts early in life. RhDNase administered as an aerosol reduces the viscosity and surface adhesivity of CF sputum. Sputum that is less viscous is easier to clear out from the lungs by mucociliary and cough clearance. Multiple clinical trials have shown 
that rhDNase is effective as therapy for $\mathrm{CF}$ in patients with mild to moderate lung disease. It improves lung function and decreases the exacerbation rate in adults and children with $\mathrm{CF}$.

Importantly, rhDNase is safe to use. Adverse reactions attributed to rhDNase are rare.

There is evidence to show that therapy with rhDNase over a 1-month period is associated with an improvement in lung function in $\mathrm{CF}$, results from a trial lasting 6 months also showed the same effect. Therapy over a 2 -year period significantly improved $\mathrm{FEV}_{1}$ in children and there was a nonsignificant reduction in the risk of infective exacerbations.

In Europe, rhDNase is approved only for CF patients aged 5 years and older, since registration studies were performed only in this age category.

All clinical indicators, including pathology, the pharmacokinetics of distribution, and some pilot efficacy studies, suggest that rhDNase will be beneficial in CF patients under 5 years old. An adequately powered, placebo-controlled trial in CF patients less than 5 years of age is difficult to perform. However, these studies are urgently needed to establish safety and efficacy especially in infants.

Use of dornase alfa is becoming increasingly common in young CF patients, to maintain lung function at its optimal level, reduce the risk of acute and chronic infection, and help delay the progression of irreversible lung disease. Early intervention is expected to preserve lung function at least as effectively as later intervention because irreversible lung damage is unlikely to be influenced by any treatment. The greatest long-term treatment benefit is therefore likely to be experienced by the youngest patients. Safety in patients under 5 years old is at least as good as in older patients. Therefore, the benefit/risk of dornase alfa in CF patients under 5 years old is at least as positive as in older patients.

The question now is not if rhDNase is an effective and safe drug. On average patients gain benefit from regular daily use of rhDNase. Unfortunately, there are no methods to more specifically determine who will benefit or who will not benefit from maintenance therapy with rhDNase. Despite RhDNase is probably the best investigated drug in $\mathrm{CF}$, however, there are weaknesses as well. Clearly, the lack of data in young children is problematic. We need also to address such problems as use of an appropriate nebulizer. Alternative day dosing has been suggested and should be investigated further. Low sputum magnesium levels have been reported in non-responders to rhDNase and this observation may have important clinical implications and deserve further investigation.

\section{Disclosures}

The author has no conflicts of interest to declare.

\section{References}

Aitken ML, Burke W, McDonald G, et al. 1992. Recombinant human DNase inhalation in normal subjects and patients with cystic fibrosis. A phase 1 study. JAMA, 267:1947-51.

Armstrong DS, Grimwood K, Carlin JB, et al. 1997. Lower airway inflammation in infants and young children with cystic fibrosis. Am J Respir Crit Care Med, 156:1197-204.

Armstrong DS, Grimwood K, Carzino R, et al. 1995. Lower respiratory infection and inflammation in infants with newly diagnosed cystic fibrosis. $B M J, 310: 1571-2$.

Armstrong DS, Hook SM, Jamsen KM, et al. 2005. Lower airway inflammation in infants with cystic fibrosis detected by newborn screening. Pediatr Pulmonol, 40:500-10.

Balough K, McCubbin M, Weinberger M, et al. 1995. The relationship between infection and inflammation in the early stages of lung disease from cystic fibrosis. Pediatr Pulmonol, 20:63-70.

Berge MT, Wiel E, Tiddens HA, et al. 2003. DNase in stable cystic fibrosis infants: a pilot study. $J$ Cyst Fibros, 2:183-8.

Boe J, Dennis JH, O’Driscoll BR, et al. 2001. European Respiratory Society Guidelines on the use of nebulizers: Guidelines prepared by a European Respiratory Society Task Force on the use of nebulizers. Eur Respir J, 18:228-42.

Bollert FGE, Paton JY, Marshall TG, et al. 1999. Recombinant DNase in cystic fibrosis: A protocol for targeted introduction through n-of-1 trials. Eur Respir J, 13:107-13.

Chen B, Costantino HR, Liu JT, et al. 1999. Influence of calcium ions on the structure and stability of recombinant human deoxyribonuclease I in the aqueous and lyophilized states. J Pharm Sci, 88:477-82.

Chernick W 1959. Comparison of tracheobronchial secretion in cystic fibrosis of the pancreas and bronchiectasis. Pediatrics, 24:739-45.

Chernick WS, Barbero GJ, Eichel HJ 1961. Invitro evaluation of effect of enzymes on tracheobronchial secretions from patients with cystic fibrosis. Pediatrics, 27:589-96.

Cobos N, Danes I, Gartner S, et al. 2000. DNase use in the daily care of cystic fibrosis: who benefits from it and to what extent? Results of a cohort study of 199 patients in 13 centres. DNase National Study Group. Eur J Pediatr, 159:176-81.

Collins FS 1992. Cystic fibrosis: molecular biology and therapeutic implications. Science, 256:774-9.

Cystic Fibrosis Foundation. 2006. Patient Registry Annual Report.

Davies J, Trindade MT, Wallis C, et al. 1997. Retrospective review of the effects of rhDNase in children with cystic fibrosis. Pediatr Pulmonol, 23:243-8.

Doring G, Høiby N 2004. Early intervention and prevention of lung disease in cystic fibrosis: a European consensus. J Cyst Fibros, 3:67-91.

Eisenberg JD, Aitken ML, Dorkin HL, et al. 1997. Safety of repeated intermittent courses of aerosolized recombinant human deoxyribonuclease in patients with cystic fibrosis. J Pediatr, 131:118-24.

Fiel SB, Fuchs HJ, Johnson C, et al. 1995. Comparison of three jet nebulizer aerosol delivery systems used to administer recombinant human DNase I to patients with cystic fibrosis. The Pulmozyme rhDNase Study Group. Chest, 108:153-6.

Frederiksen B, Pressler T, Hansen A, et al. 2006. Effect of aerosolized rhDNase (Pulmozyme) on pulmonary colonization in patients with cystic fibrosis. Acta Paediatr, 95:1070-4.

Fuchs HJ, Borowitz DS, Christiansen DH, et al. 1994. Effect of aerosolized recombinant human DNase on exacerbations of respiratory symptoms and on pulmonary function in patients with cystic fibrosis. The Pulmozyme Study Group. N Engl J Med, 331:637-42.

Harms HK, Matouk E, Tournier G, et al. 1998. Multicenter, open-label study of recombinant human DNase in cystic fibrosis patients with moderate lung disease. DNase International Study Group. Pediatr Pulmonol, 26:155-61. 
Hodson ME, McKenzie S, Harms HK, et al. 2003. Dornase alfa in the treatment of cystic fibrosis in Europe: a report from the Epidemiologic Registry of Cystic Fibrosis. Pediatr Pulmonol, 36:427-32.

Houtmeyers E, Gosselink R, Gayan-Ramirez G, et al. 1999. Effects of drugs on mucus clearance. Eur Respir J, 14:452-67.

Hubbard R, McElvaney NG, Birrer P, et al. 1992. A preliminary study of aerosolised recombinant human deoxyribonuclease in treatment of cystic fibrosis. $N$ Engl J Med, 326:812-5.

Jones AP, Wallis CE 2003. Recombinant human deoxyribonuclease for cystic fibrosis. Cochrane Database Syst Rev, (3):CD001127.

Khan TZ, Wagener JS, Bost T, et al. 1995. Early pulmonary inflammation in infants with cystic fibrosis. Am J Respir Crit Care Med, 151:1075-82.

Kirchner KK, Wagener JS, Khan TZ, et al. 1996. Increased DNA levels in bronchoalveolar lavage fluid obtained from infants with cystic fibrosis. Am J Respir Crit Care Med, 154:1426-9.

Koch C, Høiby N 1993. Pathogenesis of cystic fibrosis. Lancet, 341(8852): 1065-69.

Konstan MW, Hilliard KA, Norvell TM, et al. 1994. Bronchoalveolar lavage findings in cystic fibrosis patients with stable, clinically mild lung disease suggest ongoing infection and inflammation. Am J Respir Crit Care Med, 150:448-54.

Konstan MW, Morgan WJ, Butler SM, et al. 2007. Risk Factors For Rate of Decline in Forced Expiratory Volume in One Second in Children and Adolescents with Cystic Fibrosis. J Pediatr, 151:134-9.e1.

Lieberman J. 1968. Dornase aerosol effect on sputum viscosity in cases of cystic fibrosis. JAMA, 205:312-3.

McCoy K, Hamilton S, Johnson C, et al. 1996. Effects of 12-week administration of dornase alfa in patients with advanced cystic fibrosis lung disease. Chest, 110:889-95.

McKenzie SG, Chowdhury S, Strandvik B, et al. 2007. Dornase alfa is well tolerated: data from the epidemiologic registry of cystic fibrosis. Pediatr Pulmonol, 42:928-37.

Nasr SZ, Kuhns LR, Brown RW, et al. 2001. Use of computerized tomography and chest $\mathrm{x}$-rays in evaluating efficacy of aerosolized recombinant human DNase in cystic fibrosis patients younger than age 5 years: a preliminary study. Pediatr Pulmonol, 31:377-82.

Paul K, Rietschel E, Ballmann M, et al. 2004. Effect of treatment with dornase alpha on airway inflammation in patients with cystic fibrosis. Am J Respir Crit Care Med, 169:719-25.

Perks B, Shute JK 2000. DNA and actin bind and inhibit interleukin-8 function in cystic fibrosis sputa: in vitro effects of mucolytics. Am J Respir Crit Care Med, 162:1767-72.

Petersen NT, Høiby N, Mordhorst CH, et al. 1981. Respiratory infections in cystic fibrosis patients caused by virus, chlamydia and mycoplasma - possible synergism with Pseudomonas aeruginosa. Acta Paediatr Scand, 70:623-8.

Potter JL, Spector S, Matthews LW, et al. 1969. Studies on pulmonary secretions. 3. The nucleic acids in whole pulmonary secretions from patients with cystic fibrosis, bronchiectasis, and laryngectomy. Am Rev Respir Dis, 99:909-16.

Quan JM, Tiddens HA, Sy JP, et al. 2001. A two-year randomized, placebocontrolled trial of dornase alfa in young patients with cystic fibrosis with mild lung function abnormalities. J Pediatr, 139:813-20.

Ramsey BW, Astley SJ, Aitken ML, et al. 1993. Efficacy and safety of shortterm administration of aerosolized recombinant human deoxyribonuclease in patients with cystic fibrosis. Am Rev Respir Dis, 148:145-51.

Ranasinha C, Assoufi B, Shak S, et al. 1993. Efficacy and safety of shortterm administration of aerosolised recombinant human DNase I in adults with stable stage cystic fibrosis. Lancet, 342:199-202.

Ratjen F, Hartog CM, Paul K, et al. 2002. Matrix metalloproteases in BAL fluid of patients with cystic fibrosis and their modulation by treatment with dornase alpha. Thorax, 57:930-4.
Ratjen F, Paul K, van Koningsbruggen S, et al. 2005. DNA concentrations in BAL fluid of cystic fibrosis patients with early lung disease: Influence of treatment with dornase alpha. Pediatr Pulmonol, 39:1-4.

Riordan JR 2008. CFTR Function and Prospects for Therapy. Annu Rev Biochem, 77:701-26.

Riordan JR, Rommens JM, Kerem B, et al. 1989. Identification of the cystic fibrosis gene: cloning and characterization of complementary DNA. Science, 245:1066-73

Robinson M, Hemming AL, Regnis JA, et al. 1997. Effect of increasing doses of hypertonic saline on mucociliary clearance in patients with cystic fibrosis. Thorax, 52:900-3.

Rommens JM, Iannuzzi MC, Kerem B, et al. 1989. Identification of the cystic fibrosis gene: chromosome walking and jumping. Science, 245:1059-65.

Rosenfeld M, Gibson RL, McNamara S, et al. 2001. Early pulmonary infection, inflammation, and clinical outcomes in infants with cystic fibrosis Pediatr Pulmonol, 32:356-66.

Sagel SD, Kapsner R, Osberg I, et al. 2001. Airway inflammation in children with cystic fibrosis and healthy children assessed by sputum induction. Am J Respir Crit Care Med, 164:1425-31.

Sanders NN, Franckx H, De Boeck K, et al. 2006. Role of magnesium in the failure of rhDNase therapy in patients with cystic fibrosis. Thorax, 61:962-8.

Shah PL, Conway S, Scott SF, et al. 2001. A case-controlled study with dornase alfa to evaluate impact on disease progression over a 4-year period. Respiration, 68:160-4.

Shah PL, Scott SF, Geddes DM, et al. 1997. An evaluation of two aerosol delivery systems for rhDNase. Eur Respir J, 10:1261-6.

Shah PL, Scott SF, Geddes DM, et al. 1995. Two years experience with recombinant human DNase I in the treatment of pulmonary disease in cystic fibrosis. Respir Med, 89:499-502.

Shah PL, Scott SF, Knight RA, et al. 1996. The effects of recombinant human DNase on neutrophil elastase activity and interleukin-8 levels in the sputum of patients with cystic fibrosis. Eur Respir J, 9:531-4.

Shak S, Capon DJ, Hellmiss R, et al. 1990. Recombinant human DNase I reduces the viscosity of cystic fibrosis sputum. Proc Natl Acad Sci US A, 87:9188-92.

Smith AL, Redding G, Doershuk C, et al. 1988. Sputum changes associated with therapy for endobronchial exacerbation in cystic fibrosis $J$ Pediatr, 112:547-54.

Suri R, Marshall LJ, Wallis C, et al. 2002. Effects of recombinant human DNase and hypertonic saline on airway inflammation in children with cystic fibrosis. Am J Respir Crit Care Med, 166:352-5.

ten Berge M, van der Wiel E, Tiddens HAWM, et al. 2003. DNase in stable cystic fibrosis infants: a pilot study. J Cyst Fibros, 2:183-8.

van der Giessen LJ, de Jongste JC, Gosselink R, et al. 2007. RhDNase before airway clearance therapy improves airway patency in children with CF. Pediatric Pulmonology, 42:624-30.

Wagener JS, Rock MJ, McCubbin MM, et al. 1998. Aerosol delivery and safety of recombinant human deoxyribonuclease in young children with cystic fibrosis: a bronchoscopic study. Pulmozyme Pediatric Broncoscopy Study Group. J Pediatr, 133:486-91.

Wilson CJ, Robbins LJ, Murphy JM, et al. 2007. Is a longer time interval between recombinant human deoxyribonuclease (dornase alfa) and chest physiotherapy better? A multi-center, randomized crossover trial. Pediatr Pulmonol, 42:1110-6.

Zuelzer WW, Newton WA 1949. The pathogenesis of fibrocystic disease of the pancreas. A study of 36 cases with special reference to the pulmonary lesions. Pediatrics, 4:53-69. 
